\title{
Escola, educação integral e a Educação em Direitos Humanos
}

\author{
Ana Maria Klein 1 \\ Marina Scaramuzza Bressan ${ }^{2}$ \\ Paula Toledo Lara dos Santos ${ }^{3}$
}

\begin{abstract}
RESUMO
O presente ensaio aborda a crescente importância da escola em sociedades cada vez mais complexas e a consequente necessidade de uma educação integral que conceba o ser humano em sua multidimensionalidade e volte-se para a humanização dos estudantes. Propõe-se a formação ética e para a cidadania por meio da Educação em Direitos Humanos. Este tipo de educação, obrigatória em todos os níveis e modalidades de ensino no país, estrutura-se a partir de conhecimentos sobre os Direitos Humanos, valores como igualdade, liberdade e solidariedade e práticas que gerem ações e instrumentos em favor da promoção, da proteção e da defesa dos direitos humanos, bem como da reparação de suas violações. Este conhecimento desenvolve-se pela problematização da realidade contribuindo para a inserção social e cidadã crítica em relação às violações de direitos que ocorrem no país.
\end{abstract}

PALAVRAS-CHAVE: Educação em Direitos Humanos. Educação integral. Escola. Formação ética. Direitos Humanos.

\footnotetext{
${ }^{1}$ Doutora. UNESP, São José do Rio Preto, SP, Brasil. ORCID: https://orcid.org/0000-0002-0004-1908. E-mail: ana.klein@unesp.br.

${ }^{2}$ Mestranda. UNESP, São José do Rio Preto, SP, Brasil. ORCID: http://orcid.org/0000-0002-6731-3357. E-mail: marina.s.bressan@unesp.br.

${ }^{3}$ Mestranda. UNESP, São José do Rio Preto, SP, Brasil. ORCID: http://orcid.org/0000-0001-6546-4058. E-mail: pt.santos@unesp.br.
} 
School, integral education and Human Rights Education

\begin{abstract}
This paper discusses the growing importance of the school in increasingly complex societies and the consequent need for a comprehensive education that conceives the human being in his multidimensionality and focuses on the humanization of students. Ethical and citizenship training through Human Rights Education is proposed. This type of education, mandatory at all levels and modalities of education in the country, is structured based on knowledge about Human Rights, values such as equality, freedom and solidarity and practices that generate actions and instruments in favor of promotion, protection and the defense of human rights, as well as the repair of violations. This knowledge is developed by problematizing reality, contributing to critical social and citizen insertion in relation to the violations of rights that occur in the country.
\end{abstract}

KEYWORDS: Human Rights Education. Comprehensive education. School. Ethical training. Human rights.

Escuela, educación integral y educación en derechos humanos

\title{
RESUMEN
}

El presente ensayo aborda la creciente importancia de la escuela en sociedades cada vez más complejas y la consecuente necesidad de una educación integral que conciba al ser humano en su multidimensionalidad y se enfoque en la humanización de los estudiantes. Se propone la formación ética y ciudadana a través de la educación en derechos humanos. Este tipo de educación, obligatoria en todos los niveles y modalidades de educación, se estructura en base al conocimiento sobre los Derechos Humanos, valores como la igualdad, la libertad y la solidaridad y prácticas que generan acciones e instrumentos a favor de la promoción, protección y la defensa de los derechos humanos, así como la reparación de violaciones. Este conocimiento se desarrolla problematizando la realidad, contribuyendo a la inserción social y ciudadana crítica en relación a las violaciones de derechos que ocurren en el país.

PALABRAS CLAVE: Educación en derechos humanos. Educación integral. Escuela. Formación ética. Derechos humanos. 


\section{Introdução}

O tema desse dossiê nos instiga a refletir sobre mudanças no sistema educacional e a direção das mesmas. Trata-se de vislumbrarmos as possibilidades da educação que almejamos socialmente. A educação é um processo tão importante e central ao desenvolvimento humano e à formação para o convívio social que temos uma instituição destinada exclusivamente a este fim, a escola.

Quanto mais complexas as sociedades mais importante se torna a educação escolar, assumindo um papel instrutivo na transmissão de conhecimentos e um papel formativo que incide na formação ética e cidadã das novas gerações. Nesse sentido, a escola desejada deveria atuar por meio de uma educação integral e suas práticas orientarem-se pelos Direitos Humanos.

Este ensaio busca defender a Educação em Direitos Humanos como uma via necessária e desejável para uma educação humanizadora, que transcende a mera transmissão de conteúdos. A metodologia adotada é a revisão bibliográfica que utilizou como parâmetro linguístico obras em língua portuguesa, pois a discussão circunscreve-se à educação escolar brasileira. Como parâmetro cronológico, adotamos obras publicadas nos últimos 15 anos, após o lançamento do Plano Nacional de Educação em Direitos Humanos (BRASIL, 2007b). O parâmetro temático compreendeu os campos da Educação em Direitos Humanos e Educação Integral. Foram consultadas fontes físicas, como livros impressos e plataformas como Scielo.

Este ensaio está organizado em 4 partes, a primeira traz uma reflexão sobre o papel da escola nas sociedades, a segunda aborda a educação integral na perspectiva da formação integral do ser humano; a terceira apresenta os fundamentos e práticas da Educação em Direitos Humanos que correspondem à proposta de uma educação integral e a quarta parte traz as considerações finais. 


\section{Escola}

A escola cumpre uma função social essencial à formação das novas gerações na medida em que transmite os saberes e os valores considerados essenciais à vida em sociedade. A educação escolar, obrigatória no Brasil a partir dos 4 anos de idade e estendendo-se até o ensino médio, ocupa ao menos 13 anos da vida de crianças e adolescentes. Nessa instituição elas e eles permanecem por no mínimo quatro horas por dia, cinco dias por semana, nove meses por ano. Trata-se de uma instituição social pela qual passa (ou deveria passar), obrigatoriamente, toda a população infantil e juvenil.

Os anos escolares marcam a condição social da criança e do jovem, implicando em compromissos e responsabilidades valorizados socialmente e que transcendem os laços da vida familiar ou comunitária (ENGUITA,1989). Mas nem sempre foi assim, à medida que as sociedades se tornam mais complexas, a escola assume novas responsabilidades e torna-se mais abrangente e extensiva.

Vila (2007, p.12) destaca, no trabalho de Enguita, três momentos de mudança nas relações entre escola e sociedade: suprageracional, intergeracional e intrageracional. O primeiro momento é caracterizado pela estabilidade e poucas mudanças sociais entre uma geração e outra, localizase na antiguidade, quando apenas grupos reduzidos compostos por escribas, sacerdotes e demais membros de uma elite necessitavam de educação institucionalizada. A maioria das pessoas era educada pela família e pela comunidade, uma vez que o saber necessário para participar da vida social era passível de ser aprendido através da vida cotidiana. Trata-se de uma escola com pequeno alcance social e destinada apenas a uma elite.

A segunda mudança advém da revolução industrial e das transformações sociais impulsionadas pela mesma. Neste momento as mudanças sociais são percebidas entre uma geração e outra. A modernidade 
trouxe a passagem das sociedades agrárias para as industrializadas, o desenvolvimento científico e tecnológico, o surgimento da imprensa, a emergência dos estados modernos; enfim, mudanças que afetaram diferentes ordens da vida e se refletiram em novas necessidades educacionais. Pais, avós, comunidade já não eram mais capazes de transmitir todos os saberes necessários à participação nessa sociedade que demandava novas soluções. Por isso, parte da educação das novas gerações passou a ser desempenhada pela escola. A extensão da instituição junto à população infantil e jovem ampliou-se, mas apenas em nível elementar, pois a continuidade dos estudos implicava em seleções constantes dos discentes, perpetuando seu caráter elitista e excludente.

A terceira mudança relaciona-se à aceleração das transformações que afetam substancialmente a vida das pessoas exigindo que as novas gerações incorporem-se a um mundo no qual a informação e o conhecimento assumem um papel cada vez mais decisivo em todas as ordens da vida. Atualmente, as mudanças sociais ocorrem dentro de uma mesma geração. A formação inicial centrada na transmissão de conteúdos não é mais capaz de suprir as necessidades educacionais dos indivíduos ao longo das suas vidas, faz-se necessária uma formação mais ampla e adequada às novas demandas da vida contemporânea. Nesse cenário, a educação escolar tem mudado e agora supre a família e a comunidade em funções que outrora foram suas; tornou-se imprescindível a extensão social da escola, que proporcionou o acesso de todos e todas à escolarização básica e universalizou o ensino médio.

Na mesma linha, temos o trabalho de Esteve (2004) que aponta três momentos que caracterizam as relações entre escola e sociedade, denominados pelo autor como revoluções educacionais. A primeira revolução cria e generaliza a escola como instituição dedicada ao ensino. Documentos históricos, datados de 2.500 anos antes de Cristo, apontam para a existência de escolas no antigo Egito, destinadas à elite sacerdotal e à administração do Estado, onde se ensinava a escrever. Os poucos que tinham acesso a este privilégio estavam 
dispensados do trabalho corporal e ocupavam uma posição social relevante e economicamente vantajosa, compatível com seu grau de instrução.

A segunda revolução, datada do século XVIII, relaciona-se à responsabilidade do Estado frente à educação da população infantil: as escolas deixaram de ser apenas fruto de iniciativas aleatórias do setor privado. O compromisso estatal com a escola restringia-se ao ensino fundamental, circunscrito à alfabetização e ao domínio de cálculos elementares, com intenções claras de impulsionar o desenvolvimento econômico. A escassez de vagas oferecidas levou a uma nova elitização: só os estudantes que obtinham boas notas e que se adaptavam à instituição, correspondendo às suas exigências, conseguiam prosseguir seus estudos. Institucionalmente, esta "seleção" levou à formação de um corpo discente homogêneo, com rendimentos escolares semelhantes e expectativas convergentes. Socialmente, esta elitização resultou na distinção dos indivíduos pelo seu nível de escolarização, garantindo aos mais graduados um futuro promissor.

A primeira e a segunda revoluções são, portanto, caracterizadas por uma educação escolar elitista e excludente, concebida como privilégio e que conferia aos seus beneficiários status social e econômico.

A terceira revolução, iniciada na segunda metade do século XX, caracteriza-se pela compreensão da educação escolar como um direito, com o ensino fundamental sendo estendido a toda população, e pela obrigatoriedade do ensino médio. Conceber a educação escolar como direito de todos e todas abre as portas da instituição a amplas parcelas da população juvenil. No Brasil, a Lei de Diretrizes e Bases da Educação (BRASIL, 1996), promulgada em 1996, determina que o ensino médio integre a educação básica. Desde então, o Estado assumiu a oferta desse nível de ensino, com o objetivo de proporcionar um maior aprofundamento, além de estudos e preparação para o trabalho, formação para a cidadania, formação ética e crítica e conhecimentos capazes de relacionar a teoria à prática. 
$\mathrm{Na}$ análise de Klein e Pátaro (2008, p.2), ambos os autores, Enguita (1989) e Esteve (2004), destacam a crescente importância social da escola ao longo dos séculos, em períodos distintos, durante os quais vem cumprindo funções precisas: quem formar, para quais funções estes indivíduos serão formados e em que conteúdos formar. A educação das novas gerações, em seu percurso histórico, segue uma orientação que aponta para a crescente formalização através da universalização da escola.

A periodização proposta pelos autores, alicerçada na relação nas transformações da sociedade, através das gerações e da extensão da escola, destaca a importância crescente da instituição frente à complexidade social. Diante de uma sociedade estável, na qual as mudanças se davam muito lentamente e os conhecimentos necessários à vida social mantém-se durante gerações e gerações, a educação institucional era restrita em sua abrangência e se resumia aos saberes específicos, como a leitura e a escrita. À medida que as mudanças sociais se intensificaram, ocorrendo, entre uma geração e outra, a participação na nova ordem passou a demandar capacidades que não podiam mais ser transmitidas apenas pela família e pela comunidade; assim, a instituição escolar foi chamada a esta função em nível elementar, tendo como objetivo a transmissão de saberes como leitura e cálculo, essenciais ao desempenho de novas funções.

Vivemos, agora, uma terceira fase, na qual as mudanças sociais se dão no interior de cada geração e os saberes necessários à participação social incluem a capacidade de adaptação a uma ordem pouco estável. As instituições sociais enfrentam o desafio de se adequarem a uma ordem incerta, tornando-se mais abertas e flexíveis. A convivência social confronta as pessoas com a necessidade de desenvolverem competências sociais e cidadãs que favoreçam a convivência em um contexto marcado pelas diversidades. Tal desafio cobra processos de aprendizagem mediados pela escola que sejam capazes de transcender os conhecimentos específicos e atuem visando à 
formação mais ampla, orientados para os novos desafios sociais e comprometidos com uma educação integral.

\section{Educação integral e a formação ética}

A discussão sobre uma educação integral não é recente, Anísio Teixeira, na primeira metade do século XX, ao propor uma educação pública de qualidade já defendia a educação integral. No final da década de 1920, Teixeira, em viagem aos Estados Unidos, conhece o trabalho de John Dewey, que o influenciou diante de um cenário nacional marcado por processos de urbanização e industrialização com um grave e visível quadro de desigualdade social.

Cavaliere (2010, p. 249) analisa o contexto sócio-histórico-político no qual se inserem as ideias de uma educação em tempo integral proposta por Teixeira que, embora não usasse a expressão educação em tempo integral, defendia o aumento da jornada dos discentes em todos os níveis de ensino. A proposta de Teixeira destaca a importância de uma educação integral, alicerçada na vivência e nas experiências cotidianas como base e fonte para a construção do saber e formação moral dos alunos e alunas.

Nas décadas de 1980 e de 1990, a experiência dos CIEPs (Centros Integrados de Educação Pública) implantados durante as duas gestões de Leonel Brizola como governador do Rio de Janeiro, concretizavam a proposta de uma educação de qualidade, articulada à comunidade e em tempo integral.

A Lei $n^{\circ}$ 9.394/96 (BRASIL, 1996), que estabelece as diretrizes e bases da educação nacional, em seus artigos 34 e 87, $§ 5^{\circ}$, prevê o tempo mínimo de 4 horas de trabalho em sala de aula com ampliação progressiva do tempo de permanência na escola e os esforços conjuntos da União, estados e municípios objetivando a progressão das redes escolares públicas urbanas de ensino fundamental para o regime de escolas de tempo integral. 
Em 2007, o Ministério da Educação criou o Programa Mais Educação, por meio da Portaria Interministerial n $\mathrm{n}^{\mathrm{o}}$ 17/2007 (BRASIL, 2007a) e regulamentado pelo Decreto $n^{0} 7.083 / 10$ (BRASIL, 2010). O Programa foi uma estratégia do Ministério da Educação para fomentar a educação integral nas redes estaduais e municipais de ensino, ampliando a jornada escolar nas escolas públicas, para no mínimo 7 horas diárias, por meio de atividades optativas, tais como: acompanhamento pedagógico; educação ambiental; esporte e lazer; direitos humanos em educação; cultura e artes; cultura digital; promoção da saúde; comunicação e uso de mídias; investigação no campo das ciências da natureza e educação econômica.

Ao longo das últimas décadas do século XX e até hoje, há experiências de escola de tempo integral desenvolvidas por estados e municípios brasileiros. O governo do estado de São Paulo vem investindo em Escolas em Tempo Integral (ETI) que oferecem, no contraturno das aulas regulares, atividades esportivas e culturais. Há, também, em curso o Programa de Ensino Integral cuja matriz curricular inclui orientação de estudos, preparação para o mundo do trabalho e auxílio na elaboração de um projeto de vida.

Como vimos, a educação integral relaciona-se fortemente à ampliação do tempo de permanência na escola, sem dúvida desejável socialmente. Em nossa opinião, esta discussão, associada aos aspectos quantitativos, não deve sobrepor-se à ideia de educação integral concebida em seus aspectos qualitativos, seja na escola integral ou na de turno parcial. Dito de outra forma, não basta ampliar o tempo da jornada escolar sem a reflexão sobre a qualidade da mesma, sobre o tipo de formação que será ofertada.

A oferta de uma formação que considera a complexidade humana é defendida por Gonçalves (2006), que define a educação integral a partir da consideração do sujeito em sua multidimensionalidade, não apenas na sua dimensão cognitiva, como também na compreensão de um sujeito corpóreo, com afetos e inserido num contexto de relações. O mesmo entendimento está presente no trabalho de Tavares (2009), para quem a educação integral 
relaciona-se à formação integral do ser humano, considerando sua condição multidimensional. Araújo e Klein (2006) associam a educação integral à formação de cidadãos por meio de uma prática pedagógica intencionalmente voltada à formação em valores éticos.

A educação integral pensada neste ensaio diz respeito à concepção do ser humano em suas diferentes dimensões: cognitiva, social, afetiva e ética. Ao nascer somos biologicamente humanos, mas ainda somos incapazes de ter o comportamento que se espera de um ser humano em sociedade, precisamos aprender sobre nossa cultura, sobre valores e comportamentos éticos, precisamos conhecer nossos sentimentos e aprender a nos relacionarmos e participarmos socialmente. Apenas após aprendizagens somos capazes de viver como humanos com base em nossa história e nossa cultura. Neste sentido, a educação é um processo que pode nos humanizar, se prever ações intencionalmente voltadas ao desenvolvimento humano em sua multidimensionalidade.

Defendemos aqui a proposta de uma educação que transcenda a transmissão de conteúdos e direcione-se à formação ética e cidadã das novas gerações, uma educação humanizadora, alicerçada nos Direitos Humanos.

A indeterminação e a incompletude humanas faz com que os seres humanos sejam capazes de valorar, comparar, intervir, escolher, decidir, romper e, por tudo isso, fazerem-se éticos. No entanto, não nascemos éticos, comportamentos desta natureza requerem aprendizagem.

O autor catalão, Josep Maria Puig (ARAÚJO, PUIG, ARANTES, 2007) inspirado por Delors, Morin e Jonas, destaca 4 âmbitos relacionados à experiência humana e à aprendizagem ética: auto-ética, alter-ética, socioética, ecoética.

A auto-ética refere-se ao aprender a ser e inclui pensamento autônomo (saber o que fazer em diferentes situações); sensibilidade moral (indignar-se diante de situações inaceitáveis); regular a própria conduta (ter critérios); auto-observação (coerência). A Alter-ética corresponde ao aprender a conviver e envolve a compreensão e reconhecimento do outro 
através do estabelecimento de vínculos e compromisso com projetos em comum. Trabalhar em grupo e colaborar em projetos transformou-se num valor ético. A socioética relaciona-se ao aprender a participar e significa aprendizagem da vida em comum, formação de um cidadão ativo. Isso implica na participação, deliberação, democratização do saber (deve servir para entender o mundo), virtudes democráticas. Por fim, a ecoética diz respeito ao aprender a habitar o mundo, à responsabilidade pelo presente e pelo futuro do ser humano e do planeta. Trata-se da busca concreta de pontos de vista aceitáveis que nos ajudem a pensar numa forma de vida que seja justa e sustentável para a humanidade.

Aprender a conviver, a respeitar, a participar da sociedade são comportamentos imprescindíveis à cidadania. O conceito de cidadania, nos discursos contemporâneos das ciências sociais, não está limitado ao nível de envolvimento político formal, mas se estende ao nível social e interpessoal. As modernas concepções de cidadania acreditam que o envolvimento é um possível caminho catalisador para uma pessoa se tornar livre, autônoma e participativa (OSER \& VEUGELERS, 2008). Assim, a educação para a cidadania não se limita a aprendizagem sobre política, mas refere-se, também, à capacidade de viver uma vida social e política. Alargar o conceito de cidadania para o nível pessoal significa que devemos proporcionar às novas gerações amplo espaço para relações dialógicas e participação em processos sociais. Tornar-se um cidadão não é uma carreira pessoal, mas o resultado do esforço coletivo de indivíduos que têm ligações entre si.

A dimensão formativa da escola é alvo do trabalho de Puig et al (2000). O autor destaca que, dentre as funções socialmente delegadas à esta instituição, está a formação para a cidadania. Cada regime político requer um tipo de atuação e com a democracia acontece o mesmo, principalmente se levarmos em conta a importância e a tendência de buscar na participação ativa do cidadão uma forma de ampliação e legitimação deste sistema. $\mathrm{O}$ autor defende que a formação em valores socialmente desejáveis à cidadania democrática seja desenvolvida por meio de práticas educativas que os 
concretizam. Sua proposta parte de uma análise crítica da escola que vivenciamos atualmente, cujo discurso enfatiza a formação para a cidadania e os valores democráticos, mas que se contradiz em suas práticas.

Para Machado (2000), a cidadania deve ser entendida num sentido amplo, que transcende o direito a ter direitos e implica, também, numa formação que contribua para a promoção destes direitos, através da participação ativa na sociedade, com a assunção de responsabilidades relativas aos interesses e destinos de uma coletividade, o que representa a essência da cidadania.

Uma educação integral comprometida com a formação ética e para a cidadania democrática deve guiar-se por conhecimentos, valores e práticas pedagógicas que possibilitem a convivência em uma sociedade justa, que respeita e promove os direitos de todas as pessoas.

\title{
Educação em Direitos Humanos
}

O texto a seguir é atribuído a uma vítima do nazismo e foi encontrado em um campo de concentração.

\begin{abstract}
Prezado Professor, sou sobrevivente de um campo de concentração. Meus olhos viram o que nenhum homem deveria ver. Câmaras de gás construídas por engenheiros formados. Crianças envenenadas por médicos diplomados. Recém-nascidos mortos por enfermeiras treinadas. Mulheres e bebês fuzilados e queimados por graduados de colégios e universidades. Assim tenho minhas suspeitas sobre a Educação. Meu pedido é: ajude seus alunos a tornarem-se humanos. Seus esforços nunca deverão produzir monstros treinados ou psicopatas hábeis. Ler, escrever e saber aritmética só são importantes se fizerem nossas crianças mais humanas.
\end{abstract}

A carta dirigida aos professores nos leva a algumas indagações. Basta formar as novas gerações para o trabalho? Dominar os conteúdos escolares e saber desenvolver uma profissão é suficiente para integrar a sociedade? Basta adaptar as pessoas à sociedade tal qual ela se encontra? 
Nossas respostas a todas às indagações anteriores é "não". A educação deve ser um processo de humanização que não acontece apenas na escola, mas tem nesta instituição sua principal via para a formação dos membros das novas gerações.

O que esperamos das pessoas nas suas atuações sociais, nas suas relações com as pessoas, na sua participação cidadã? Nossas expectativas, nossa visão de sociedade e de ser humano, é que guiam as ações educativas.

Em uma sociedade democrática, esperamos que haja o reconhecimento de que todos os seres humanos são dignos e ninguém pode receber tratamento cruel, discriminatório, sofrer tortura ou ser discriminado. A dignidade humana reconhece a posição eminente do ser humano em relação às outras espécies, enquanto ser dotado de razão e de sentimentos; trata-se de um atributo que independe de merecimento pessoal ou social, pois ela é inerente à vida. Sociedades democráticas e compostas pelas diversidades, como a brasileira, necessitam de uma educação que habilite as pessoas a reconhecerem no outro um ser de direitos e de dignidade. Estamos em um país marcado por colossais desigualdades sociais que, muitas vezes, levam à invisibilidade do outro e à negação de seus direitos. Na maioria das vezes que nos referimos aos Direitos Humanos no Brasil, temos um triste e revoltante cenário de violações que ferem a dignidade humana, princípio central dos Direitos Humanos.

Direitos Humanos são frutos da luta pelo reconhecimento, realização e universalização da dignidade humana. São princípios e valores baseados na igualdade, o que pressupõe a consideração e o reconhecimento do "outro" como um ser humano, igual a mim. São questões que envolvem os conceitos de alteridade e reciprocidade, que colocam o eu e o outro como sujeitos e objetos da ética. Atuar na promoção de direitos e na conscientização sobre os mesmos nos leva à importância da educação e nas possibilidades do que pode ser feito.

Educação e Direitos Humanos são interdependentes e se articulam de duas maneiras: educação é um direito humano que possibilita ao ser 
humano o desenvolvimento de suas potencialidades; ao mesmo tempo, os Direitos Humanos dependem da educação para que sejam conhecidos, valorizados e promovidos socialmente. Esta dupla relação entre educação e Direitos Humanos está presente na Declaração Universal dos Direitos Humanos (ONU, 1948): no preâmbulo do documento destaca-se a educação como caminho para a realização de todos os direitos e no artigo 26 a educação é concebida como um direito.

No Brasil, o compromisso do Estado com uma educação fundamentada nos Direitos Humanos se deu por meio do Plano Nacional de Educação em Direitos Humanos, PNEDH (BRASIL, 2018), cuja primeira versão data de 2003. Em 2012, o Conselho Nacional de Educação promulgou Diretrizes Nacionais para Educação em Direitos Humanos (BRASIL, 2012b), tornando este tipo de educação obrigatória em todas as etapas e modalidades educacionais do país.

O Plano Nacional de Educação em Direitos Humanos, PNEDH, define a Educação em Direitos Humanos como um processo sistemático e multidimensional, ou seja, não é pontual ou um marco de chegada, é um caminho trilhado diariamente e que envolve diferentes dimensões: conhecimentos sobre Direitos Humanos, valores éticos, formação cidadã, metodologias participativas e práticas que gerem ações e instrumentos em favor da promoção, da proteção e da defesa dos direitos humanos, bem como da reparação das violações (BRASIL, 2018, p. 11)

O Parecer CNE/CP N N $^{\circ}$ /2012 (BRASIL, 2012a) que origina as Diretrizes Nacionais para a Educação em Direitos Humanos destaca a formação de sujeitos de direitos e responsabilidades comprometidos com a democracia e com o fortalecimento de grupos que têm seus direitos violados num contexto social marcado por desigualdades e injustiças. Este documento adota a perspectiva de uma educação ética, crítica e emancipadora. A formação pretendida é ética na medida em que se orienta por valores humanizadores; crítica, pois implica na reflexão e na prática que problematiza contextos sociais, culturais, econômicos e 
políticos; e é política, pois prevê a formação de sujeitos de direitos capazes de exercer ativamente sua cidadania, de se organizar, de dialogar, reivindicar direitos e lutar pela sua conquista.

$\mathrm{O}$ documento destaca sete princípios que fundamentam a $\mathrm{EDH}$ :

1. Dignidade humana;

2. Igualdade de direitos;

3. Reconhecimento e valorização das diversidades e diferenças;

4. Laicidade no Estado;

5. Democracia na educação;

6. Transversalidade, vivência e globalidade;

7. Sustentabilidade ambiental.

Tais princípios referem-se aos direitos dos sujeitos e a uma existência pautada por valores de justiça e equidade, destaca a democracia como um processo que deve orientar as relações institucionalmente, marca a importância da relação entre direitos humanos e vivência de todos os envolvidos na comunidade escolar e nos direitos das gerações futuras.

A inserção da EDH nos currículos pode se dar de diferentes maneiras: pela transversalidade, por meio de temas relacionados aos Direitos Humanos e tratados interdisciplinarmente; como um conteúdo específico de uma das disciplinas já existentes no currículo escolar; e de maneira mista, ou seja, combinando transversalidade e disciplinaridade.

No entanto, a EDH não se limita às aulas, independentemente da via escolhida é preciso um amplo espaço de reflexão envolvendo toda a comunidade escolar a fim de planejar ações destinadas à criação de um ambiente comprometido com os direitos humanos. Este deve ser um trabalho intencionalmente voltado a tal finalidade durante o qual devem ser discutidas formas de relacionamento e normas de convivência, metodologias de trabalho e técnicas avaliativas que considerem o estudante como elemento central no processo ensino-aprendizagem, valores democráticos e humanizadores que se concretizam nas relações cotidianas. 
A EDH objetiva a construção de ambientes educativos promotores de direitos, este tipo de educação constitui-se como um modo de vida capaz de orientar todas as relações que têm espaço nos ambientes escolares e na sociedade.

Os Direitos Humanos tratam basicamente de relacionamentos, consequentemente envolvem relações de poder entre indivíduos, grupos, sociedade ou Estado, portanto são históricos, sociais e políticos. É preciso que se tenha consciência desta dimensão para que a EDH não se transforme em mera transmissão de informações sobre direitos já estabelecidos e desvinculados de seu contexto de luta e conquista.

[...] qualquer esperança de promover o contato das pessoas com a consciência crítica e com a ação social está diretamente relacionada à sua capacidade de refletir sobre experiências e situações que tocam profundamente a sua vida (BUTKUS, apud MEINTJES, 2007, p. 134).

A variedade de relações entre seres humanos é ampla, o que torna os direitos humanos dinâmicos, em constante discussão, reivindicação e transformação. Por isso, a EDH se desenvolve em contextos reais, a partir de experiências, necessidades e problemas dos sujeitos (estudantes, comunidade escolar, comunidade na qual a escola se localiza) e das relações destes entre si, com a sua escola, sua comunidade e com o seu governo.

\section{Conclusões}

A complexidade das sociedades atuais requer cada vez mais a ampliação da atuação da escola enquanto instituição social destinada à formação das novas gerações visando o convívio e a participação social, por este motivo, a educação integral, concebendo a multidimensionalidade do ser humano, torna-se desejável na medida em que se volta à formação ética e cidadã dos estudantes. Esta formação pretendida deve caminhar 
no sentido da humanização das pessoas, por meio do reconhecimento da igualdade, da dignidade e dos Direitos Humanos.

A Educação em Direitos Humanos compreende conhecimento e informações sobre os Direitos Humanos, a formação ética (valoração positiva dos direitos e de seus princípios) e a prática (saber fazer valer este direitos e a responsabilidade social com a sua realização). Esta formação deve acontecer a partir e por meio da realidade social, assim a aprendizagem se dá pela problematização da realidade e ao fazer isso evidenciam-se situações de violações de direitos, violações estas que poderiam ser invisibilizadas se não fosse o posicionamento crítico em relação às mesmas. Trata-se de desnaturalizar discriminações e violências, desta maneira, espera-se que os estudantes construam uma visão de mundo crítica e cidadã e sejam capazes de compreender a realidade e, desejavelmente, atuar no sentido de transformá-la.

Por fim, retomando a ideia inicial de refletir sobre mudanças no sistema educacional e a direção das mesmas, sentimos falta de uma educação humanizadora que eduque meninos e meninas para o reconhecimento e valorização dos seres humanos em toda a sua diversidade de modos de ser, viver, pensar, sentir e existir. Novas gerações que sejam incapazes de cometer as atrocidades que pessoas educadas foram capazes de cometer em nome de uma ideologia discriminatória como foi o nazismo. Educar para que a cegueira passional movida pelo ódio e por ideais nacionalistas radicais não se repitam na história da humanidade.

\section{Referências}

ARAÚJO, Ulisses F.; KLEIN, Ana Maria. Escola e comunidade, juntas, para um cidadania integral. Cadernos Cenpec| Nova série, v. 1, n. 2, p.119-125, 2006. Disponível em:

http://cadernos.cenpec.org.br/cadernos/index.php/cadernos/article/view/134.

Acesso em: 04 out. 2020. DOI:

http://dx.doi.org/10.18676/cadernoscenpec.v1i2.134.

ARAÚJO, Ulisses F.; KLEIN, Ana Maria; PUIG,Josep Maria; ARANTES, Valéria Amorim (Org). Educação e valores: pontos e contrapontos. 2 ed. São Paulo: Summus, 2007. 168 p. 
BRASIL. Decreto n. 7.083, de 27 de janeiro de 2010. Dispõe sobre o Programa Mais Educação. Diário Oficial da União, Brasília, DF, p.2-3, 27 jan. 2010. Edição extra - Seção 1. Disponível em: http://www.planalto.gov.br/ccivil 03/ ato20072010/2010/decreto/d7083.htm. Acesso em: 13 out. 2020.

BRASIL.Lei n. 9.394, de 20 de dezembro de 1996. Estabelece as diretrizes e bases da educação nacional. Diário Oficial da União, Brasília, DF, p. 27, 23 dez. 1996. Seção 1. Disponível em:

https://www2.camara.leg.br/legin/fed/lei/1996/lei-9394-20-dezembro-1996362578-publicacaooriginal-1-pl.html. Acesso em: 04 out. 2020.

BRASIL. Portaria Normativa Interministerial n. 17, de 24 de abril de 2007. Institui o Programa Mais Educação que visa fomentar a educação integral de crianças, adolescentes e jovens, por meio do apoio a atividades sócio-educativas no contraturno escolar. Diário Oficial da União, Brasília, DF, p.5-6, 26 abr. 2007. Seção 1. Disponível em: http://portal.mec.gov.br/arquivos/pdf/mais_educacao.pdf. Acesso em: 04 out.2020.

BRASIL. Comitê Nacional de Educação em Direitos Humanos. Plano Nacional de Educação em Direitos Humanos. Brasília, DF: Secretaria Especial dos Direitos Humanos, Ministério da Educação, Ministério da Justiça, UNESCO, 2007. 76 p. Disponível em: http://portal.mec.gov.br/docman/2191-planonacional-pdf/file. Acesso em: 12 out. 2020.

BRASIL. Ministério da Educação. Conselho Nacional de Educação. Conselho Pleno. Parecer n. 8, de 06 de março de 2012. Diretrizes Nacionais para a Educação em Direitos Humanos. Diário Oficial da União, Brasília, DF, p.33, 30 mai. 2012. Seção 1. Disponível em:

http://portal.mec.gov.br/index.php?option=com_docman\&view=download\&al ias=10389-pcp008-12-pdf\&category_slug=marco-2012-pdf\&Itemid=30192.

Acesso em: 13 out. 2020.

BRASIL. Ministério da Educação. Conselho Nacional de Educação. Conselho Pleno. Resolução n.1, de 30 de maio de 2012. Estabelece Diretrizes Nacionais para a Educação em Direitos Humanos. Diário Oficial da União, Brasília, DF, p. 48, 31 maio 2012. Seção 1. Disponível em:

http://portal.mec.gov.br/dmdocuments/rcp001_12.pdf. Acesso em: 12 out. 2020.

BRASIL. Ministério dos Direitos Humanos. Comitê Nacional de Educação em Direitos Humanos. Plano Nacional de Educação em Direitos Humanos. Brasília, DF: Comitê Nacional de Educação em Direitos Humanos, 2018. 50 p. Disponível em: https://www.gov.br/mdh/pt-br/navegue-por-temas/educacao-emdireitos-humanos/DIAGRMAOPNEDH.pdf. Acesso em: 12 out. 2020. 
CAVALIERE, Ana Maria. Anísio Teixeira e a educação integral. Paidéia, Ribeirão Preto, SP, v. 20, n. 46, pág. 249-259, mai./ago. 2010. Disponível em: http://www.scielo.br/scielo.php?script=sci arttext\&pid=S0103863X2010000200012\&lng=en\&nrm=iso. Acesso em: 05 out. 2020. DOI: http://dx.doi.org/10.1590/S0103-863X2010000200012.

ENGUITA, Mariano Fernandez. A face oculta da escola. Porto Alegre, RS: Artes Médicas, 1989. 272 p.

ESTEVE, José M. A terceira revolução educacional: a educação na sociedade do conhecimento. São Paulo: Moderna, 2004. 207 p.

GONÇALVES, Antonio Sérgio. Reflexões sobre educação integral e escola de tempo integral. Cadernos Cenpec | Nova série, São Paulo, SP, v. 1, n. 2, p.129-135, ago. 2006. Disponível em:

http://cadernos.cenpec.org.br/cadernos/index.php/cadernos/article/view/136/168. Acesso em: 05 out. 2020. DOI: http://dx.doi.org/10.18676/cadernoscenpec.v1i2.136.

KLEIN, Ana Maria; DE OLIVEIRA PÁTARO, Cristina Satiê. A escola frente às novas demandas sociais: educação comunitária e formação para a cidadania. Cordis: Revista Eletrônica de História Social da Cidade, n. 1, 2008. Disponível em: https://revistas.pucsp.br/cordis/article/view/10312. Acesso em: 12 out. 2020.

MACHADO, Nilson José. Educação: projetos e valores. 5 ed. São Paulo, SP: Escrituras Editora, 2000. 157 p.

MEINTJES, Garth. Educação em Direitos Humanos para o Pleno Exercício da Cidadania. In CLAUDE, Richard; ANDREOPOULOS, George J (orgs). Educação para os Direitos Humanos no Século XXI. São Paulo: Editora da Universidade de São Paulo - Núcleo de Estudos da Violência, 2007.

ORGANIZAÇÃO DAS NAÇÕES UNIDAS - ONU. Assembleia Geral das Nações Unidas. Declaração Universal dos Direitos Humanos. Paris: Assembleia Geral das Nações Unidas, 1948. Disponível em:

https://brasil.un.org/sites/default/files/2020-09/por.pdf. Acesso em: 13 out. 2020.

OSER, Fritz K.; VEUGELERS, Wiel (Eds.). Getting involved: Global Citizenship Development and Sources of Moral Values. Rotterdam: Sense Publishers, 2008. 381p.

PUIG, Josep Maria et al. Democracia e participação escolar: propostas de atividades. São Paulo, SP: Editora Moderna, 2000. 215 p. 
TAVARES, Celma. Educação integral, educação contextualizada e educação em direitos humanos: reflexões sobre seus pontos de intersecção e seus desafios. Acta Scientiarum. Human and Social Sciences, Maringá, PR, v. 31, n. 2, p. 141-150, 2009. Disponível em: http://www.periodicos.uem.br/ojs/index.php/ActaSciHum anSocSci/article /view/5436. Acesso em: 12 out. 2020. DOI:

https://doi.org/10.4025/actascihumansoc.v31i2.5436.

VILA, Julio Vera. Las relaciones escuela y comunidad em um mundo cambiante. In: CASTRO RODRIGUEZ, M.M. et al. La escuela em La comunidade: La comunidad em la escuela. Barcelona: Editorial Grão, 2007. p.11-38.

Recebido em outubro de 2020.

Aprovado em janeiro de 2021. 